\title{
Earthquake physics and real-time seismology
}

\author{
Hiroo Kanamori
}

\section{The past few decades have witnessed significant progress in our understanding of the physics and complexity of earthquakes. This has implications for hazard mitigation.}

Simply stated, an earthquake is caused by slip on a fault. However, the slip motion is complex, reflecting the variation in basic physics that governs fault motion in different tectonic environments. Seismologists can learn a great deal about earthquakes from studying the details of slip motion.

\section{The size of great earthquakes}

Seismic slip motion involves a broad 'period' (or frequency) range, at least from $0.1 \mathrm{~s}$ to 1 hour, and a wide range of amplitudes, roughly from $1 \mu \mathrm{m}$ to $30 \mathrm{~m}$. Most seismographs available before the 1960 s could record ground motions over only short periods - less than $30 \mathrm{~s}$ - which prevented seismologists from studying important details of earthquake processes. In the 1960s, longer-period analogue seismographs became available, allowing seismologists to study great earthquakes (in general, magnitude $\geq 8$ ) over an extended period range; this has resulted in substantial progress in our understanding of earthquakes. For example, being able to measure long-period waves of up to 1 hour has made it possible for seismologists to establish the overall size of great earthquakes accurately. With the old instruments, wave amplitudes were measured over only a short period range, leading to underestimates of the magnitude of great earthquakes (Fig. 1). The monitoring of longperiod waves, combined with rigorous use of wave theory, rectified this problem, and, as a result, our perception of global seismicity changed drastically during the twentieth century. With the old estimates, global seismic activity seemed to have been relatively constant over the century, but according to the new estimates, a burst of activity occurred between 1952 and 1965; about 40\% of the total seismic energy released during the century was released during this period (see ref. 1 for a review).

Another important finding is that most earthquakes involve a relatively low stress change, 1-10 MPa. This contrasts with the much higher stress - $100 \mathrm{MPa}$ or greater - involved in fracture of rocks at high confining pressure. This indicates that the fracture process in Earth's crust involves special physics, and this is currently the subject of extensive research.

A better understanding of great earthquakes has also contributed to an improved understanding of the relationship between earthquakes and global plate motion.

\section{Earthquake diversity}

Since the late 1970s, force-balanced seismographs, which can record ground motions over a very broad period range (from $0.02 \mathrm{~s}$ to hours) and have a large dynamic range in amplitude (a factor of $10^{7}$ in the ratio of the smallest to the largest amplitude $)^{2}$, have become widely used. These instruments revolutionized observational seismology, and the fact that they are networked on a global scale, as well as a regional scale, has been especially useful (see page 266). Studies with broadband seismographs revealed a remarkable diversity of earthquakes in terms of slip characteristics and energy budget. Figure 2a shows the temporal diversity of energy release in earthquakes. Some earthquakes slip slowly and others rapidly, depending on the tectonic environment in which they occur. This diversity not only has important implications for seismic hazard but also provides important clues about the fundamental physics of earthquakes. Subduction-zone earthquakes with slow slip tend to generate unexpectedly large tsunamis (for instance, the 2006 Java tsunami, represented by a red curve in Fig. 2a). Those earthquakes that occur within the subducting slab (for example, the Kuril Islands earthquake of 2007, denoted by a black curve in Fig. 2a) tend to have faster slip and can cause much stronger shaking than those with comparable magnitudes that occur on the subduction boundary (for example, the Kuril Islands earthquake of 2006, denoted by a blue curve in Fig. 2a). At present, these special characteristics are not fully considered in hazard-mitigation practices, and they need to be more explicitly considered in the future.

With an increased density of strong-motion seismographs deployed in many seismically active areas, together with geodetic data obtained using global positioning systems (GPS) and satellite interferometry,

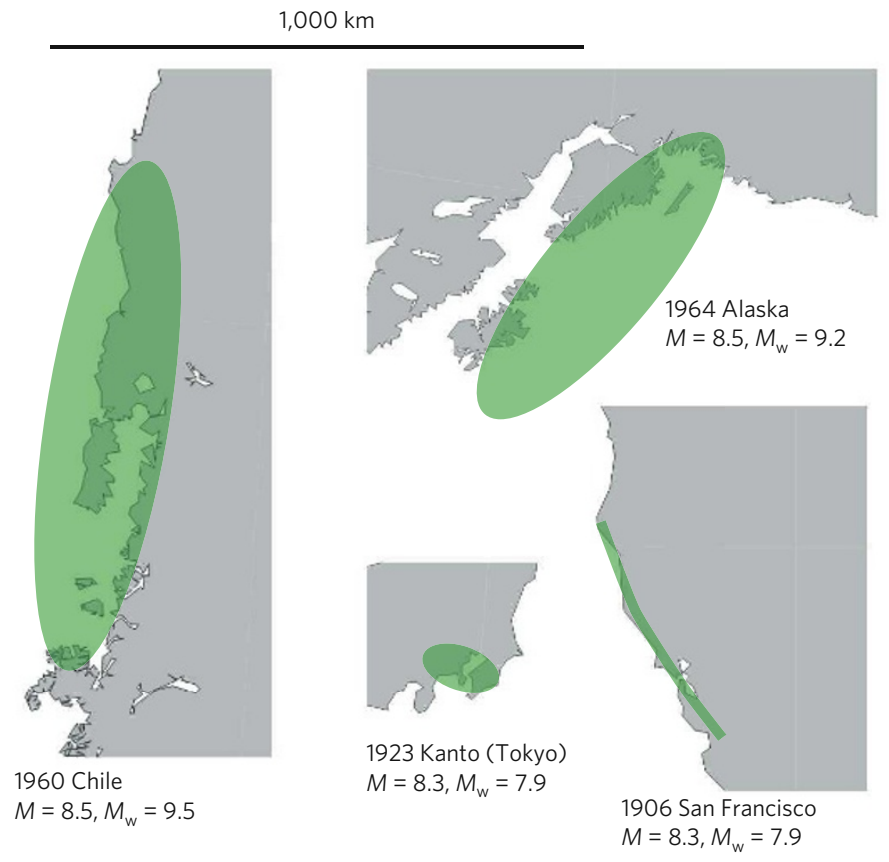

Figure 1 | Comparison of rupture area and magnitude. Use of very longperiod ( $>200 \mathrm{~s}$ ) waves removed the saturation problem of the old surfacewave magnitude, $M$, which saturates above 8 and gives approximately the same values for great earthquakes regardless of the size of the rupture area inferred mainly from the aftershock area. $M_{\mathrm{w}}$ is the magnitude determined using long-period waves with a rigorous source theory and is known as the moment magnitude. Illustrated in this figure are the comparisons of the rupture areas (green) and the magnitude (both $M$ and $M_{\mathrm{w}}$ ) for the 1960 Chilean earthquake, the 1964 Alaskan earthquake, the 1923 Kanto (Tokyo) earthquake and the 1906 San Francisco earthquake. The aftershock region of the 2004 Sumatra-Andaman earthquake $\left(M_{w}=9.2\right)$ was about $1,400 \mathrm{~km}$ long - even longer than that of the 1960 Chilean earthquake. 
a
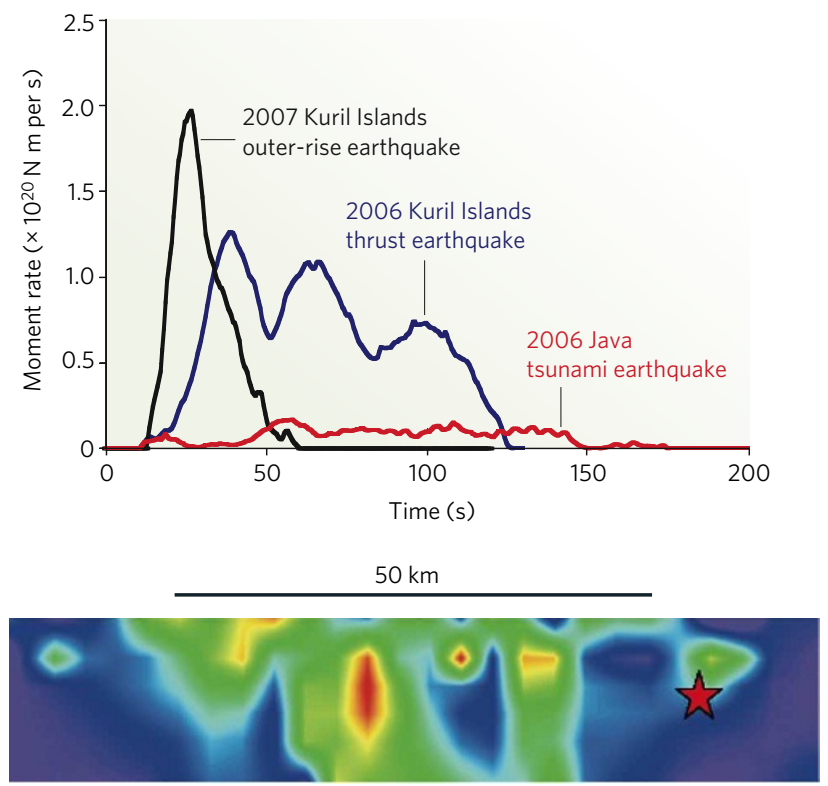

Figure 2 | Temporal and spatial diversity of seismic slip. a, Moment rate function, which is roughly proportional to the energy release rate at the source as a function of time, for three earthquakes. The blue curve represents a great (magnitude $\left(M_{\mathrm{w}}\right)$ 8.3) subduction-zone thrust earthquake that occurred in the Kuril Islands on 15 November 2006. This behaviour is typical of most earthquakes that occur on a boundary between an oceanic and a continental plate. The black curve is for a great $\left(M_{w}=8.1\right)$ outer-rise earthquake that took place in the Kuril Islands on 13 January 2007. This event occurred within the subducting plate. The red curve represents a slow tsunami earthquake that occurred off the coast of Java on 17 July 2006. (Panel modified, with permission, from ref. 13.) b, Spatial rupture pattern of the Landers earthquake that hit California on 28 June 1992 (ref. 14). The star indicates where the rupture began. Red areas indicate the patches with the largest slip, about $6 \mathrm{~m}$. The spatial variation of slip indicates the variation of stress and frictional properties, which can be used to study rupture physics. These properties also control the strength and frequency content of strong ground motions. $\mathrm{N} \mathrm{m}$, newton metre.

more details of seismic slip motion became clear. In old fault models, fault slip was treated as a spatially uniform slip propagating at a constant speed. This picture is still useful for understanding the general properties of fault motion, but it is very simplistic. The slip heterogeneity revealed by recent studies is often characterized by terms such as 'asperities' and 'barriers', as shown in Fig. 2b, which demonstrates the spatial diversity of seismic slip. Asperities are the portions on a fault at which large slip occurs, and barriers are patches where fault motion is impeded. Asperities and barriers reflect the heterogeneities of stress, the frictional properties of faults and geometries, and have a key role in the nucleation, growth and cessation of slip motion. The frictional properties depend on not only the static condition on the fault but also the slip velocity itself, and the resulting slip motion can exhibit highly complex patterns. Fault friction is the subject of active theoretical, laboratory and field studies, and various elementary processes including melting, fluid pressurization, fault lubrication and microfracturing have been examined ${ }^{3}$.

Sudden changes in rupture propagation caused by asperities and barriers control the strength and complexity of strong ground motions. Modern ground-motion estimates take advantage of the detailed slip models obtained recently. Models that take asperities and barriers into account are expected to provide much more realistic information about ground motion, which will be useful to engineers designing earthquakeresistant structures.

These studies using broadband seismographs also demonstrate the importance of taking into account the effects of long-period waves excited by large (in general, magnitude $<8$ ) and great (magnitude $\geq 8$ ) earthquakes when designing tall buildings and large structures ${ }^{4,5}$.
Towards multi-scale science

Most seismologically measured parameters are macroscopic in that they represent the quantity integrated over the entire fault motion. Such parameters include seismic moment (a quantity proportional to the product of the amount of slip and the fault area), radiated energy, fault dimension and the change in stress (that is, the stress drop). In cases in which near-field measurements are available, local slip functions and stress changes at every point on the fault can also be determined ${ }^{6}$. The relationship between the slip and the stress is called the 'fault constitutive relation' and can bridge the macroscopic fault parameters and the microscopic properties studied in theoretical, laboratory and field investigations. In this sense, seismology has become an intellectually challenging, multi-scale science that attempts to integrate traditional macroscopic seismological properties, medium-scale fault constitutive relations, and microscopic theoretical-laboratory-field parameters to obtain a comprehensive physical model of seismic rupture processes (see ref. 7 for more details).

\section{Slow and silent earthquakes}

Recent studies using GPS and high-density seismic networks extended the measurable period range to days, months and years, which led to the discovery of slow and silent earthquakes ${ }^{8}$. From early seismological studies, some earthquakes were known to be slow, with a timescale longer than a few minutes, but these recent studies demonstrated the existence of seismic events with even longer timescales, which are often associated with small tremors ${ }^{9}$. It is generally agreed that these events occur on the downward extension of the seismogenic megathrust boundary at subduction zones and of crustal faults (Fig. 3). They represent the transitional behaviour from shallow brittle failure to deeper creeping motion. Many studies suggest that fluids released from hydrous minerals carried by the subducting slab are responsible for silent events at subduction zones. Although the details are still under extensive investigation, these events probably influence the state of stress in the adjacent seismogenic boundary, and the current interest is focused on whether the activity of silent events can provide a clue to the occurrence of large megathrust earthquakes in the same region. This problem is particularly important in the Cascadia subduction zone, which stretches, just offshore, along the northwest coast of North America, and the Nankai trough, off the coast of southwest Japan, where historical great megathrust earthquakes have been documented in detail, and where similar great earthquakes are certain to occur again.

Whether the physics of silent earthquakes is similar to, or entirely different from, that of regular earthquakes is an interesting scientific question. Although their timescales differ markedly, it is possible that the basic physics is the same and that the timescale difference is just a result of different energy partition between the radiated and dissipated energy. If so, what is responsible for the difference in partition? By contrast, the deformation mechanism can differ substantially: for example, brittle failure on a plane (regular earthquakes) versus volumetric slow deformation (silent earthquakes). This is one of the most exciting research topics at present.

\section{Real-time seismology and earthquake early warning}

Even though seismologists have made considerable progress in understanding the basic physics of earthquakes, precise short-term earthquake predictions are still difficult to make because a large number of interacting elements are involved in the nucleation, growth and termination of an earthquake. At present, it is almost impossible to determine all the minute details that contribute to the occurrence of an earthquake. However, a better understanding of the overall physics of stress accumulation and release processes will improve our ability to carry out long-term forecasting of seismicity in many active areas in the world. With the accumulation of more data and improved methodology, long-term forecasting, in conjunction with improved engineering practice, will hopefully contribute significantly to the mitigation of seismic hazard in the future.

Significant progress has been made in the area of real-time seismology. 


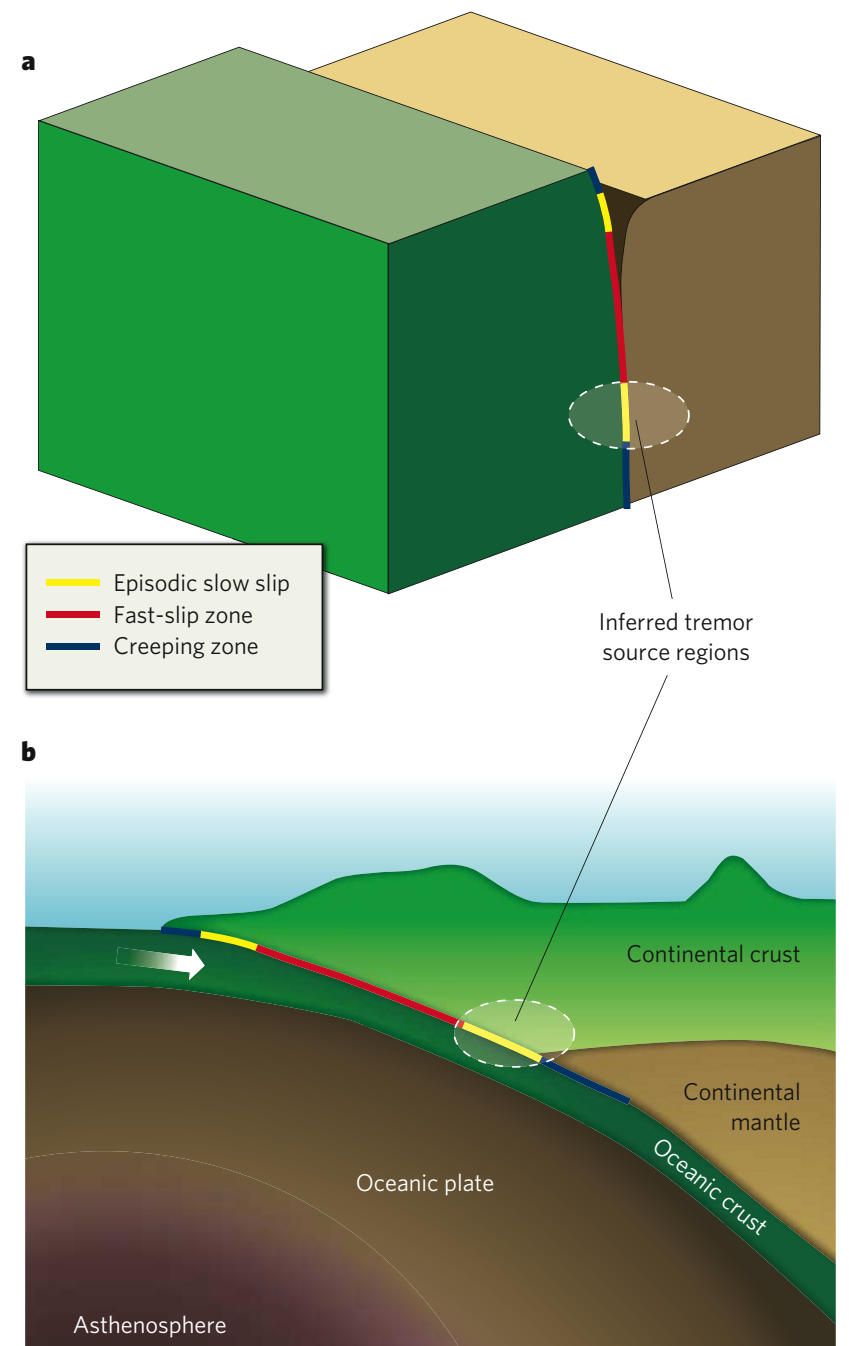

Figure 3 | Locations of brittle fast-slip (seismogenic) and slow-slip zones. a, Vertical strike-slip fault. b, Subduction-zone boundary. (Figure adapted, with permission, from ref. 15).

Real-time seismology refers to a practice by which we rapidly estimate, immediately after a significant earthquake, the source parameters and the distribution of shaking intensity, and distribute the information to various users. These users include emergency services officials, utility companies, transportation services, the media and the general public. This information will be useful for reducing the impact of a damaging earthquake on our society ${ }^{10}$.

In most cases, it takes minutes to hours to process the data, and by the time the information reaches the users, the damage may already have occurred at the user site. In this case, the information is called post-earthquake information. This information is important for orderly recovery operations in the damaged areas. A good example of this post-earthquake information is ShakeMap (http://earthquake.usgs. gov/eqcenter/shakemap) ${ }^{11}$.

By contrast, if the data processing and information transfer can be done very rapidly (for instance, within $10 \mathrm{~s}$ ), the information reaches some sites before shaking starts there. In such cases, the information is called 'earthquake early warning' (see ref. 12 for more details). This concept has been around for more than 100 years but was not put into practice until recently owing to technical and practical difficulties. In Japan, a warning system for impending ground shaking after a nearby large earthquake was implemented in the 1960s in conjunction with the operation of the high-speed bullet train. This system led to the subsequent development of earthquake early-warning methods for more general purposes. Several earthquake early-warning methods have been developed recently in many countries, and some have already been implemented. For example, in Japan, early-warning information is being distributed to the public and holds the promise of being a practical way to mitigate earthquake damage. Now that technical capability has been demonstrated, the next important step is to educate the public and to use early-warning information effectively through the judicious use of modern technology, such as control engineering.

Hiroo Kanamori is at the Seismological Laboratory, California Institute of Technology, Pasadena, California 91125, USA.

1. Kanamori, H. The diversity of the physics of earthquakes. Proc. Jpn Acad. B 80, 297-316 (2004).

2. Wieland, E. \& Streckeisen, G. The leaf-spring seismometer: design and performance. Bull. Seismol. Soc. Am. 72, 2349-2367 (1982).

3. Rice, J. R. \& Cocco, M. in Tectonic Faults: Agents of Change on a Dynamic Earth (ed. Handy, M. R., Hirth, G. \& Hovius, N.) 446 (Massachusetts Inst. Technology Press, Cambridge, Massachusetts, 2007).

4. Olsen, K. B., Archuleta, R. J. \& Matarese, J. R. Three-dimensional simulation of a magnitude 7.75 earthquake on the San Andreas fault. Science 270, 1628-1632 (1995).

5. Heaton, T. H., Hall, J. H., Wald, D. J. \& Halling, M. W. Response of high-rise and baseisolated buildings to a hypothetical $M_{w} 7.0$ blind thrust earthquake. Science $\mathbf{2 6 7 , 2 0 6 - 2 1 1}$ (1995).

6. Ide, S. \& Takeo, M. Determination of constitutive relations of fault slip based on seismic wave analysis. J. Geophys. Res. 102, 27379-27392 (1997).

7. Abercrombie, R., McGarr, A., Di Toro, G. \& Kanamori, H. (eds) Earthquakes: Radiated Energy and the Physics of Faulting: Geophysical Monograph 170 (Americal Geophysical Union, Washington DC, 2007).

8. Dragert, H., Wang, K. \& James, T. S. A silent slip event on the deeper Cascadia subduction interface. Science 292, 1525-1528 (2001).

9. Obara, K. Nonvolcanic deep tremor associated with subduction in southwest Japan. Science 296, 1629-1681 (2002).

10. Kanamori, H. Real-time seismology and earthquake damage mitigation. Annu. Rev. Earth Planet. Sci. 33, 195-214 (2005).

11. Wald, D. J. et al. TriNet 'ShakeMaps': rapid generation of peak ground motion and intensity maps for earthquakes in southern California. Earthquake Spectra 15, 537-555 (1999).

12. Gasparini, P., Manfredi, G. \& Zschau, J. (eds) Earthquake Early Warning Systems (Springer, Berlin, 2007).

13. Ammon, C. J., Kanamori, H. \& Lay, T. A great earthquake doublet and seismic stress transfer cycle in the central Kuril islands. Nature doi:10.1038/nature06521 (in the press).

14. Wald, D. J. \& Heaton, T. H. Spatial and temporal distribution of slip for the 1992 Landers, California, earthquake. Bull. Seismol. Soc. Am. 84, 668-691 (1994).

15. Schwartz, S. Y. in Treatise of Geophysics (ed. Shubert, G.) (Elsevier, Oxford, in the press).

Author Information Reprints and permissions information is available at npg.nature.com/reprints. Correspondence should be addressed to the author (hiroo@gps.caltech.edu). 